\title{
Situational Influences on Team Helping Norms: Case Study of a Self-directed Team
}

\author{
P. Robert Duimering \\ University of Waterloo \\ Robert B. Robinson (deceased)
}

\begin{abstract}
A case study investigated the behavioral characteristics of a self-directed work team, and properties of the team's task situation that may have influenced team behavior. Results indicate that helping among team members was the most prominent group norm, and also suggest various situational factors may have encouraged helping behavior, including task flexibility, low task interdependence, asynchronous demand variability, and the lack of formal performance measures. Implications for future research and management practice are discussed. The paper contributes toward a better understanding of the behavioral characteristics of effective teams and the influence of task situation on team behavior.
\end{abstract}

\section{Introduction}

Many studies have investigated the antecedents of work team effectiveness (Cohen \& Bailey, 1997; Guzzo \& Dickson, 1996; Ilgen, Hollenbeck, Johnson, \& Jundt, 2005; Levine \& Moreland, 1990), but relatively little is known about the group norms characterizing how the members of effective teams behave and interact with one another while doing their work. Understanding the content of team behavior and norms requires close attention to the context and work situation of teams, but most studies of team effectiveness have used cross-sectional survey methods that define behavior in generic terms and overlook unique properties of team task situations that influence member behavior. This paper describes a case study which used qualitative, inductive methods over a period of six months to investigate the behavioral and situational characteristics of an effective self-managed team in a manufacturing organization. The findings indicate that helping among members was the dominant behavioral norm within the team and suggest that diverse properties of the team's task situation and organizational context contributed to the emergence of helping as a strong team norm. The results contrast views of helping as a discretionary extra-role organizational citizenship behavior (Organ, Podsakoff, \& MacKenzie, 2006; Smith, Organ, \& Near, 1983), or a type of contextual performance distinct from employee tasks (Borman \& Motowidlo, 1993; Motowidlo \& Van Scotter, 1994), and raise questions for future research on the role of helping behavior in teams and the influence of task situation on team norm development. The next section of the paper reviews the literature on team behavior and effectiveness. The case study findings will then be presented in detail, followed by a discussion of the results and their implications for research and managerial practice. 


\section{Background}

Hackman (1987) defined an effective work team as one that produces satisfactory performance output, uses social processes that facilitate continuing member interaction, and satisfies the personal needs of members. Numerous cross-sectional studies have investigated the antecedents of team effectiveness during the last twenty years (Cohen \& Bailey, 1997; Guzzo \& Dickson, 1996; Ilgen, Hollenbeck, Johnson, \& Jundt, 2005; Levine \& Moreland, 1990; Sanna \& Parks, 1997). Several potential antecedents of team effectiveness have been investigated, including: (a) properties of the organizational environment in which teams operate, such as the provision of training and managerial support (Campion, Medsker, \& Higgs, 1993), consistency between how team responsibilities are defined (e.g., individual vs. group) and how managers distribute rewards to members (Wageman, 1995), and leadership style (Wageman, 2001); (b) team design characteristics such as task interdependence (Johnson, 1973; Kiggundu, 1983), job design (Campion, Medsker, \& Higgs, 1993; Cohen \& Ledford, 1994; Cohen, Ledford, \& Spreitzer, 1996), member knowledge and skill diversity (Bunderson \& Sutcliffe, 2002; Campion, Medsker, \& Higgs, 1993), and team size (Nieva, Fleishman, \& Reick, 1985; Steiner, 1972); (c) group processes such as member communication and collaboration (Seers, Petty, \& Cashman, 1995; Vinokur-Kaplan, 1995), conflict (Jehn, 1995), and external communication with other teams (Ancona, 1990); and (d) psychosocial factors like cohesiveness, member affect, and member-group identification (Evans \& Dion, 1991; Gully, Devine, \& Whitney, 1995; Mullen, Anthony, Salas, \& Driskell, 1993; Mullen \& Copper, 1994).

Most relevant to the current study is research related to team norms (Feldman, 1984), referring to stable, regular patterns of group behavior and associated expectations that influence ongoing member behavior. Norms regularize diverse aspects of group behavior, including decision making (McClelland, 1984), task performance, interactions with outsiders (Gersick, 1988), and the pacing of group activity (Kelly \& McGrath, 1985). Studies of norm development in experimental groups (Bettenhausen \& Murnighan, 1985) suggest that norms are influenced by members' prior experiences and behavioral scripts (Abelson, 1976) imported from similar group settings. Experimental (Hackman \& Morris, 1975) and field studies (Gersick, 1988) have found that groups establish persistent behavioral routines very soon after group formation. This suggests that groups may establish norms at the first encounter of a given behavioral circumstance, and stick with these norms until novel situations requiring different behavior patterns are encountered, existing patterns lead to failure, or a natural milestone in a group's development provides the impetus for self-evaluation and behavioral change (Gersick, 1988; Gersick \& Hackman, 1990).

Few studies have investigated the relationship between behavioral norms and team effectiveness. One aspect of group norms is their relative strength, or degree of crystallization, reflecting the level of agreement among members about the appropriateness of particular behaviors. Cohen et al. (1996) found that norm crystallization was positively related to effectiveness and to several group design factors considered in their study. Theoretically, behavioral norms should reduce uncertainty by 
helping group members predict the responses of others in situations requiring coordination. Reduced uncertainty should increase efficiency and reduce member anxiety (Argyris, 1969), as groups handle similar circumstances more or less automatically, without needing to spend time and effort developing an appropriate behavioral response (Gersick \& Hackman, 1990). On the other hand, normative behavior can have dysfunctional consequences for organizations, if groups establish norms restricting production output (Roethlisberger \& Dickson, 1956; Trist \& Bamforth, 1951; Whyte, 1955), if groups misinterpret situational cues and respond habitually to circumstances requiring novel response, or if the convenience of an available routine inhibits innovation and the search for more efficient practices (Gersick \& Hackman, 1990).

Very little empirical research has investigated the content of team norms-that is, the specific kinds of behaviors reflecting what team members do when they interact with one another or with external groups during the course of their work. Norm content is highly dependent on the properties of the immediate task situation in which a team works, because behavior patterns develop as group members collectively perform specific tasks in particular organizational settings. Understanding how effective teams behave, therefore, requires close attention to situational properties, including the nature of the product or service produced, the tasks performed by team members, the connections between tasks, patterns of task-related interactions between members, and interactions between the team and external actors in the team's immediate environment. Most empirical team research has relied on the use of cross-sectional survey methods, however, which cannot capture such detailed situational characteristics and define team behaviors in more general terms (e.g., absenteeism rates), or consider generic properties of norms (e.g., degree of crystallization) that can be compared across different situations.

Team helping behavior was particularly relevant to the present study, as noted previously. Researchers have generally viewed helping as a type of discretionary, extrarole organizational citizenship behavior (OCB; Organ, Podsakoff, \& MacKenzie, 2006; Smith, Organ, \& Near, 1983), or as a type of contextual performance behavior distinct from employee task performance (Borman \& Motowidlo, 1993; Motowidlo \& Van Scotter, 1994; Organ, 1997), rather than as a normative in-role behavior that is part of how team members conceive of their tasks. Organ (1997) has suggested redefining the OCB construct in line with Borman and Motowidlo's (1993) definition of contextual performance, which treats helping as one of several kinds of extra-task rather than extra-role behaviors in organizations. Because the prevailing literature in this area has continued to use the term OCB, rather than contextual performance, to refer to such extra-role or extra-task behaviors (e.g., Organ, Podsakoff, \& MacKenzie, 2006), we follow suit in this paper. Studies have found that helping OCB is positively related to organizational effectiveness (Podsakoff, Ahearne, \& MacKenzie, 1997; Walz \& Niehoff, 2000), and various potential antecedents of helping have been investigated. The prevalence of helping OCB has been linked to employee satisfaction (Organ \& Ryan, 1995; Williams \& Anderson, 1991), personality (Borman \& Motowidlo, 1993; King, George, \& Hebl, 2005; Motowidlo \& Van Scotter, 1994; Porter, Hollenbeck, Ilgen, Ellis, 
\& West, 2003), and other attitudinal and dispositional factors (Organ, Podsakoff, \& MacKenzie, 2006). Helping OCB has also been related to situational factors such as leadership behavior (Podsakoff, MacKenzie, Paine, \& Bachrach, 2000; Sparrowe, Soetjipto, \& Kraimer, 2006) and certain job design characteristics. For example, Podsakoff, MacKenzie, and Bommer (1996) found evidence that altruism OCB (which includes helping) was related to task feedback, task routinization, and intrinsic task satisfaction. Farh, Podsakoff, \& Organ (1990) found that altruism was positively related to task scope, a measure combining task autonomy, task significance, task identity, task feedback, and task variety. Pearce and Gregerson (1991) found that reciprocal task interdependence was positively related (and task independence was negatively related) to individuals' "felt responsibility", which in turn was positively related to a measure of extra-role behavior that included some helping items. A few studies have examined OCB within the context of teams. Podsakoff et al. (1996) found evidence that OCB was related to group cohesiveness. Bishop, Scott and Burroughs (2000) studied the influence on OCB of members' perceived support from their teams, and found that effects were mediated by members' own commitment to the team, which could imply a tendency for individuals receiving help from other team members to reciprocate in kind. Deckop, Cirka and Andersson (2003) similarly found a positive relationship between supervisors' ratings of team member helpfulness toward other members and members' own ratings of the extent to which they felt helped by other members.

Prior research on team effectiveness is limited in several ways. By using cross-sectional survey methods, team effectiveness studies have had difficulty examining the content of behavioral norms in effective teams, and the unique properties of team task situations that may influence norm development. Helping, as a particular kind of team behavior, has been primarily viewed in the literature as a discretionary extra-role OCB, or a contextual performance behavior distinct from employee tasks, rather than an in-role behavior that may be expected and normative for team members and part of how they understand and organize their tasks. Few OCB studies have considered helping within a team context, and like the team effectiveness literature, OCB researchers have mainly used cross-sectional methods that have difficulty detecting properties of team task situations which may influence the prevalence of helping behavior.

This study contributes by investigating the behavioral norms of an effective self-directed team in relation to its immediate organizational task situation. In-depth inductive methods were used to examine internal and external patterns of team member interaction and behavior, to identify how members conceptualize team performance, and to identify aspects of the task situation that may have influenced member behavior. The constructs considered in the study are the result of an inductive attempt to explain patterns that emerged in observational and interview data. Some of these constructs are consistent with past research but others reflect unique influences on team behavior peculiar to the situation studied. As a qualitative study of a single team, the study can not address questions of causality among situational and behavioral variables. However, by providing a rich, holistic account of the behavioral and situational characteristics of an effective team, the study offers suggestions about potential influences among variables for consideration in future research. 


\section{Case Study}

\section{Background and Scope}

The study investigated a self-directed work team in the Final Assembly department of a large manufacturing firm over a period of six months. The firm produced industrial electronics products at several international locations and the study was conducted in its largest North American factory. The plant employed approximately 200 management and support staff and 450 unionized production workers in four departments: Circuit Pack Assembly, Frame Assembly, Final Assembly and System Test. The Circuit Pack department assembled electronic circuit boards, which fit into large metal frames produced in the Frame department. The Final Assembly department inserted circuit packs into frames to complete the manufacturing process and the System Test department verified product quality prior to shipping. Corporate management had directed local factory managers to implement self-directed teams as part of an improvement program called "Team Directed Work Force." Training materials and courses were provided for production employees and managers, a resource person was assigned to the manufacturing departments to encourage and support team efforts, and team development objectives were included in factory managers' performance evaluation. The study began approximately four months after the launch of the Team Directed Work Force program.

This study focused on team activities in the Final Assembly department, though all four production departments were involved in team implementation. The Final Assembly team was selected because factory managers and staff involved in the implementation program described it as the most effective team in the factory. The program had met with variable success, so managers wished to understand the behavioral characteristics of the Final Assembly team and hoped to emulate them elsewhere in the factory. For example, managers complained that materials provided by the corporate Human Resources department gave little practical direction about how to organize teams and did not provide concrete examples of how teams should operate in a factory setting. Circuit Pack and Frame Assembly were the largest departments with about 200 employees each; System Test had about 40 employees. First level managers in these departments each supervised 20-25 employees and were formally responsible for implementing teams in their work units. By the time the study began, these managers had reported certain team achievements, but by and large, the implementation was perceived to be encountering difficulties and progressing slowly. Most of the teams in these departments were engaged in process improvement activities separate from members' regular production jobs, and team membership was voluntary to avoid the risk of workers complaining to their Union that jobs were being unilaterally redefined by management. Final Assembly was a smaller department of 10 employees who had been operating without a first level manager for eight months prior to the launch of the team program. The former first level manager had been fired after a period of prolonged worker-management conflict. Instead of replacing the first level manager, the department manager had encouraged the employees to operate as a self-directed team 
by taking full responsibility for the department's daily operations and administrative activities. They were responsible for meeting production demands, interacting with other departments on production matters, scheduling their work and overtime hours, and filling out payroll time sheets.

The study was designed to address two objectives. Given that management and staff perceived the Final Assembly team to be performing effectively, one goal was to characterize its performance in behavioral terms-that is, to describe how this effective team behaved. A second goal was to identify aspects of the team's immediate task situation that may have influenced the emergence of its particular behavioral characteristics. More specifically, because teams in other production departments were perceived to be performing less effectively than the Final Assembly team, even though they were all working in the same general organizational environment, managers wished to understand whether there were specific properties of the Final Assembly task situation that contributed to the team's relative effectiveness.

\section{Methods}

Observational and semi-structured interview methods were used to investigate team activities in the Final Assembly department. The study investigated activities within the context of the team's immediate work situation by examining interactions between members, and between the team and other factory groups, to identify aspects of the situation that either supported or hindered its performance as a self-directed team. This paper primarily emphasizes the results of interviews with Final Assembly team members. Observational data are included where appropriate to illustrate or expand on interview results.

Two researchers spent one to two days per week over six months, observing and interacting with Final Assembly team members, their department manager, and support staff. Interactions included observations of production work, informal discussions, and participation in department meetings, planning sessions, and team training programs. Factory production reports, training materials and other documents were also collected. Observations were usually documented in handwritten notes during discussions or shortly afterward. A video camera was occasionally used to record conversations and observations of the team at work. Direct observation and participation helped us to understand context-specific activities and local jargon and provided a means of triangulating interview results to mitigate potential method bias.

Semi-structured interviews lasting one to two hours each were conducted with the 10 Final Assembly team members after three months of observation. The interview method was designed to investigate team members' task-related interactions with other team members, and with other individuals and groups outside the team. To identify members' task-related social networks, they were asked to identify other individuals or groups with whom they routinely communicated and interacted in the course of performing jobrelated tasks. Open-ended questions based on the "echo" method of Bavelas (1942; see also Cunningham, 2001) were then used to examine interactions among 
interdependent actors in these networks from the perspective of each team member. The echo method identifies positive and negative aspects of an interviewee's subjective task situation, by eliciting concrete examples of others' "good" and "not so good" taskrelated behaviors. Additional questions examined members' job activities and perceptions of team performance. Interview responses were coded by the researchers to identify the major categories of behavior affecting team members. Responses were first coded separately by two researchers, producing two sets of behavioral categories. Areas where the two categorization schemes differed were then discussed and the two schemes combined into one. The results were presented and discussed with Final Assembly team members and their manager, resulting in a few further modifications to the classification scheme. The number of interviewees and the number of behavioral examples per category are used in this paper as indicators of relative category importance.

\section{$\underline{\text { Results }}$}

This section documents the following results: (a) team members' job activities, (b) patterns of communication, workflow, and task interdependence among team members and between the team and other factory groups, (c) interactions within the team and with external groups, (d) members' perceptions of team task structure, (e) members' perceptions of team performance, and (f) observations about team size, product size, turnover rates and management style. These diverse aspects of the Final Assembly team situation are documented to provide a holistic view of the team's behavioral characteristics and the variety of situational factors affecting behavior. In summarizing the results, we attempt to identify potential relationships among them, and use the results to identify evidence of team effectiveness based on common indicators in the literature (e.g., cohesiveness, autonomy, norm strength).

\section{$\underline{\text { Job Activities }}$}

Table 1 summarizes the main job activities identified by team members and the number reporting each activity. Three points are worth noting: (a) of the 12 tasks identified, all but 2 were performed by at least 2 members, (b) individual members each performed from 3 to 7 different activities (average 4.5), and (c) 6 of the 10 members identified "helping where needed" as one of their main job activities, the highest frequency of any activity mentioned. These results indicate that helping one another was a significant role expectation within the group and that individuals had sufficient knowledge of various department tasks to be able to provide help when needed. They also indicate significant task flexibility within the team, such that the group was able to adjust individual activities in response to extra demand pressures at any point in the operation. For example, when a circuit pack shipment arrived from an external supplier, several people would drop what they were doing to help unload the boxes. 
Communication links, task interdependence and demand variability

To examine task interdependence, interviewees were asked to identify the individuals or groups with whom they communicated and interacted most while performing their jobs. Table 2 summarizes both internal links within the team and external links with other individuals or groups. Most notable is that relatively few internal links were identified explicitly. All but one member identified a link with one of three individuals who performed team coordination tasks, but only 3 other internal links were identified explicitly and 3 members stated that they interacted with "all others" in the department. These results suggest the highest degree of task-related interdependence among members was with respect to the team coordinator role, which interfaced with the Production Control department and represented an important source of information about updated hot lists and schedule priorities. On the other hand, there was little interdependence between other team members, whose tasks could be performed relatively independently.

Table 1: Final Assembly Job Activities

\begin{tabular}{lc}
\hline Job Activities & No. team members $(\mathrm{n}=10)$ \\
\hline Helping where needed & 6 \\
Receive frames/packs into inventory & 6 \\
Fill frames & 5 \\
Stock packs & 5 \\
Disperse frames/packs from inventory & 5 \\
Fill loose pack orders & 5 \\
Unload shipments & 4 \\
Team coordinator role & 3 \\
Enter and clear shortages & 2 \\
Prioritizing 'hot' packs & 2 \\
Pick from repair & 1 \\
Barcode frames/packs & 1 \\
\hline Team members per activity & Mean $=3.75$ (range 1 to 6) \\
Activities per team member & Mean $=4.5$ (range 3 to 7) \\
\hline
\end{tabular}

This pattern of communication among members was closely related to department workflow arrangements. In general, work flowed through Final Assembly along several parallel paths, with most tasks performed by individuals working alone on concurrent activities. For example, a frame could be assembled by one member whether or not a circuit pack shipment was being simultaneously unloaded by another. This parallel arrangement of relatively independent tasks created a situation in which workload demands fluctuated asynchronously across team members. With respect to the above job activity data, this parallel task structure created both the need for helping as a routine job activity and also provided team members with opportunities to help one another when needed. Those with more demand pressure required help from others, while those under less pressure had time to provide necessary help with the expectation that the favor would soon be reciprocated. By contrast, in sequential tasks 
arrangements (e.g., assembly lines) demand fluctuations tend to be experienced simultaneously by all individuals involved, such that helping is difficult during periods of high demand and unnecessary during periods of low demand.

Table 2: Internal and External Communication Links

\begin{tabular}{lc}
\hline Individuals or groups identified & No. people identifying link $(\mathrm{n}=10)$ \\
\hline Internal Links & 9 \\
\hline Team coordinator & 3 \\
Another specified team member & 3 \\
All others & \\
External Links & 6 \\
System Test & 5 \\
Production Control & 4 \\
Circuit Pack Assembly & 3 \\
Computer technician & 2 \\
Frame Assembly & 2 \\
Packaging/Shipping & 2 \\
Department manager & 1 \\
External supplier & 1 \\
Engineering & \\
\hline
\end{tabular}

External communication links identified most frequently by team members were the System Test, Production Control, and Circuit Pack departments, corresponding to the physical flow of material from Circuit Pack through Final Assembly to System Test, and the flow of information to and from Production Control associated with scheduling priorities and material availability. Less frequently mentioned were links related to the flow of material from the Frame department and an external supplier, and links to the Packaging/Shipping department, technical support groups, and the department manager. Compared to internal links, the frequency and variety of external links indicated that task interdependence was higher between team members and individuals in external units than among members of the team itself. The parallel arrangement of internal tasks indicates mainly pooled interdependence among members, but interdependencies with external units were mainly sequential or reciprocal in nature (Thompson, 1967). It is notable that although 9 of 10 members had identified an internal link with the team coordinator role, only 2 identified a link to the department manager, suggesting she played a relatively minor role in the team's daily activities, and that members perceived a degree of autonomy with respect to the team's ability to manage its own affairs.

Strong external links to Circuit Pack, System Test and Production Control reflected the fact that both Circuit Pack and System Test were capacity bottleneck operations within the factory, requiring considerable planning and communication on the part of team members in conjunction with staff in the Production Control department. Circuit Pack was often unable to meet its daily production schedules and keep Final Assembly supplied with circuit packs, usually due to shortages of electronic components from 
suppliers. Meanwhile, even after late circuit packs arrived in Final Assembly, the downstream System Test facility was unable to process more than one or two late frames of a particular configuration at a time, due to capacity constraints. Final Assembly, therefore, played the role of a reservoir between two bottlenecks, which further contributed to its asynchronous demand variability that both required and enabled team members to help one another on a routine basis. For example, if team member A was waiting for a delivery of late circuit packs, the pressure to complete her current frame assembly task decreased, since it could not be completed anyway, giving her time to help others under greater pressure for task completion. After A's late packs arrived, pressure would increase to assemble the late frames quickly, and A could meet this demand with the help of other team members under lower pressure. Once the System Test facility was filled to capacity, however, A's pressure would again subside, allowing others to return to their regular tasks and again giving her time to help them if needed. The parallel task arrangement meant that demand pressures constantly varied across members in this way, so those under less pressure could help those under more pressure and members receiving help could be expected to reciprocate when their pressure subsided.

Interactions within the Final Assembly Team

For each communication link identified, team members were asked to provide examples of these others' behaviors that were "good" and "not so good" from the point of view of their own jobs. Table 3 summarizes member behaviors internal to the team as well as responses to a similar set of questions asking for examples of "good" and "not so good" things the Final Assembly group did as a whole (as opposed to individual members). The responses provide an indication of the group's task-related behavioral norms and several points are worth noting. First, the responses were very similar whether the questions referred to individual members or to the team as a whole. This suggests evidence of high group cohesiveness as members saw little difference between their dyadic relationships with individual members and their relationship with the group as a whole. Based on the ratio of the number of positive to negative behavioral examples (i.e., 33:2 with respect to individuals and 30:6 with respect to the group) it is clear that members viewed the group very positively and were far more likely to experience "good" behaviors from one another than "not so good" behaviors. Two categories collectively accounted for over two thirds of the responses, suggesting group members viewed the norm of "helping each other" as an important aspect of team interactions and also valued the team's "positive group characteristics". The large number of comments about positive group characteristics suggests high positive affect among members and strong identification with the group, again indicating high cohesiveness. The few negative behaviors identified were mainly attributed to specific individuals who occasionally neglected responsibilities or argued. Such attributions also indicate member identification with the group, as negative behaviors were rationalized as deviations from positive group norms on the part of specific individuals.

These results can be compared to preceding data on job activities and communication links. The emphasis on "helping each other" corroborates the finding that "helping where 
needed" was the job activity mentioned most frequently by team members, providing further evidence for the strength of this group norm. The only positive behaviors attributed to an individual group member were those associated with the team coordinator role, the internal communication link identified most by team members. On the other hand, the fact that eight of ten interviewees mentioned "helping each other" suggests interactions among team members were quite prevalent after all, even though internal communication links were hardly ever identified explicitly. Besides the parallel task arrangement discussed earlier, the strength of the helping norm provides another potential reason few links were mentioned. Helping among team members was essentially routine and automatic, to the extent that explicit communication was unnecessary and members helped each other without waiting to be asked. This interpretation is supported by numerous direct observations. For instance, when a batch of late circuit packs arrived, the member receiving them would usually be aware if another member was waiting for them, and typically delivered them to the other's work station without saying anything or being asked. An example of such routine helping even occurred during one of the interviews. The interviewee noticed that another team member was having trouble reaching a container of circuit packs on an overhead roller conveyor, so she stood up without stopping what she was saying and rolled the container within the other's reach.

Table 3: Positive and Negative Team Behaviors

\begin{tabular}{|c|c|}
\hline $\begin{array}{l}\text { Behavior category (No. people [n=10], No. } \\
\text { examples) }\end{array}$ & Examples \\
\hline \multicolumn{2}{|l|}{ Good team member behaviors } \\
\hline Members helping each other $(8,17)$ & "If there's a rush, everyone helps." \\
\hline Positive group characteristics $(6,9)$ & "Friendly attitude." "Think for yourself." \\
\hline Helpful things the coordinator does $(4,5)$ & "Leaves a list of hot frames to do first." \\
\hline Miscellaneous $(2,2)$ & "Keep the material going." \\
\hline \multicolumn{2}{|l|}{ Team member behaviors that are not so } \\
\hline \multicolumn{2}{|l|}{ good } \\
\hline $\begin{array}{l}\text { Individuals neglecting responsibilities }(1,2) \\
\text { Good things the group does }\end{array}$ & "Leave problems for others to clean up." \\
\hline Members helping each other $(7,10)$ & "We give a hand and help each other." \\
\hline Positive group characteristics $(6,16)$ & $\begin{array}{l}\text { "We work well together." } \\
\text { "People are tolerant." }\end{array}$ \\
\hline Quick service to customers $(2,3)$ & "We get hot items out fast." \\
\hline Coordinator ability\& experience $(1,1)$ & "Most have 20 or more years seniority." \\
\hline \multicolumn{2}{|l|}{ Things the group does that are not so } \\
\hline good & \\
\hline Individuals neglecting responsibilities $(3,3)$ & $\begin{array}{l}\text { "Sometimes people don't return empty } \\
\text { containers to the storage area." }\end{array}$ \\
\hline $\begin{array}{l}\text { Problems/arguments between individuals } \\
(2,3)\end{array}$ & $\begin{array}{l}\text { "Lots of little fights here. But problems } \\
\text { get worked out here, not in the } \\
\text { meetings." }\end{array}$ \\
\hline
\end{tabular}




\section{$\underline{\text { Interactions with External Groups }}$}

Table 4 summarizes the "good" and "not so good" behaviors of external groups identified by team members. In contrast to internal behaviors, there were almost three times as many negative as positive examples for external links (26:9), implying that norms of interaction with external groups were characterized by considerably more negative than positive behaviors. Even some of the positive behaviors identified in Table 6 were not overwhelmingly positive, but suggest external groups were seen as helpful when they met minimum expectations of "doing what they're supposed to" and correctly "providing information." Indeed, the opposite behaviors may have been relatively more common, as suggested by negative comments about "quality problems" and "no information" in Table 4. External and internal interactions also differed in terms of the level of abstraction at which behaviors were described. The behaviors of external groups tended to be quite specific to the tasks performed (e.g., "material volume and flow problems", "container/packaging problems", "data problems", etc.) suggesting interactions did not extend much beyond meeting minimum task requirements. On the other hand, the idea of "helping each other" internally reflects a kind of abstract, generic meta-norm, implying a generally positive, supportive and flexible interaction approach, applicable to almost any behavioral circumstance on the job.

Table 4: Behavior of External Groups

Behavior category (No. people

$[\mathrm{n}=10]$, No. examples)

Examples

Good

Doing what they're supposed to

$(3,3)$

Providing information $(3,3)$

Help with problem solving $(2,3)$

Friendly and cooperative $(2,2)$

Manager's style $(2,2)$

Not so Good

Material volume and flow

problems $(4,7)$

Quality problems $(4,6)$

No information/consultation re

changes $(3,4)$

Container/packaging problems

$(3,3)$

Data problems $(2,3)$

"Just doing a good job."

"Information from Production Control on hot lists."

"If there's a problem, CP test is helpful."

"They are very obliging."

"Tells us to do our own thing and look for new work."

"Production Control can't decide where the packs should go, and we don't have room for them."

"Paint scratches on circuit packs."

"Engineers still have no discussions with workers.

You come in on Monday morning and find the system has changed."

"Containers disappear everyday. We find them all over."

"Testers take stock without a stock transfer on the night shift. Sometimes they forget to remove it from stock."

Need more involvement/

"Need more cooperation from other areas." cooperation $(2,3)$ 


\section{Perceptions of Team Structure}

To further investigate their perceptions of group interactions, a sports analogy was used to ask team members to rate on a 7-point scale whether they thought their group functioned most like a swim team (1) or a hockey team (7). It was explained that the members of a swim team shared the same coach and encouraged one another during competitions but that winning races was largely the result of individual performance, whereas the members of a hockey team needed to work closely together and coordinate their individual activities (e.g., using passing plays) for the team as a whole to be successful. The average response was 5.5 and 8 of 10 members indicated that the team was more like a hockey team than a swim team. Only 1 indicated the team was more like a swim team and 1 chose the mid-point on the scale. The fact that most perceived the group to be more like a hockey team than a swim team contrasts with the earlier findings related to the parallel structure of tasks and communication links. Though tasks could be objectively described as relatively independent, team members subjectively experienced them as quite interdependent. The strong helping norm potentially explains these perceptions. Although tasks could be performed in isolation, in fact individuals depended significantly on the help of others to cope with fluctuating demands and other difficulties on the job. Routine helping, therefore, implied that tasks exhibiting pooled interdependence in theory, were subjectively experienced as reciprocally interdependent in practice (Thompson, 1967).

\section{Perceptions of Team Performance}

Although managers and staff described the Final Assembly group as a very effective team, the department manager stated at the outset of the study that she had been unable to define quantitative measures of team performance based on standard factory indicators of production volume or quality. She explained that because of the department's location in the factory workflow between the bottleneck operations of Circuit Pack and System Test, evaluating performance in terms of production volume or schedule attainment would be "like using a speedometer to track a car's performance in a traffic jam." Similarly, the nature of the product made it difficult to evaluate team members on the quality of their work, because defects detected by System Test were usually attributable to circuit pack component failures rather than errors in Final Assembly. Because quantitative performance data were unavailable or unreliable, openended interview questions were used to investigate members' subjective perceptions of team performance. They were asked to identify any specific measures used to evaluate department performance and to describe how they personally evaluated both departmental and individual job performance. Responses are summarized in Table 5.

Several characteristics are notable in these results. First, there were no generally agreed-upon formal performance measures identified by team members, consistent with the manager's inability to define quantitative performance measures. Instead, team members paid attention to diverse informal sources of information about individual and team performance, including comments by the department manager, complaints from other groups or team members, and members' own direct perceptions of how smoothly 
the operation was running. The diversity of feedback information used by team members suggests they understood team performance in holistic rather than particularistic terms.

\section{Table 5: Performance criteria identified by team members}

\begin{tabular}{|c|c|}
\hline $\begin{array}{l}\text { Performance criteria (No. people } \\
\text { [n=10], No. examples) }\end{array}$ & Examples \\
\hline \multicolumn{2}{|l|}{ Team Performance } \\
\hline $\begin{array}{l}\text { Smooth operation/no problems } \\
(5,11)\end{array}$ & $\begin{array}{l}\text { "If frames keep going in and out, and we're not } \\
\text { back scheduling." }\end{array}$ \\
\hline $\begin{array}{l}\text { Feedback from department } \\
\text { manager }(4,5)\end{array}$ & $\begin{array}{l}\text { "The manager says we're doing well and to keep it } \\
\text { up. She also tells us if we're not doing well." }\end{array}$ \\
\hline Numerical data $(4,5)$ & "We get a final inspection report daily." \\
\hline Complaints from other groups & "We would find out if we were behind." \\
\hline$(4,4)$ & "The number of complaints from the test area." \\
\hline No measures $(2,3)$ & "I don't think there are formal measures." \\
\hline Personal record keeping $(1,1)$ & $\begin{array}{l}\text { "I keep a record of circuit pack shortages on all } \\
\text { frames daily." }\end{array}$ \\
\hline \multicolumn{2}{|l|}{ Individual Performance } \\
\hline$\overline{\text { Keeping caught up }(5,6)}$ & $\begin{array}{l}\text { "Keeping caught up on all the stuff that comes } \\
\text { through." }\end{array}$ \\
\hline $\begin{array}{l}\text { People would complain } \\
\text { otherwise }(3,3)\end{array}$ & "If I wasn't doing a good job, I'd hear about it." \\
\hline Feeling good about work $(2,2)$ & "We feel we're doing OK." \\
\hline Personal record keeping $(1,1)$ & "I keep records for inventory and data accuracy." \\
\hline
\end{tabular}

Second, most responses referred to sources of qualitative rather than quantitative performance information. Only 5 of 41 examples referred to various types of "numerical data" while 3 suggested "no measures" of team performance were taken. Many organizational studies have documented unintended effects of performance measurement on behavior. For instance, performance measures rarely capture all significant aspects of a job, so their use can lead to goal displacement where employees focus efforts narrowly on aspects of work that are measured and ignore aspects that are not measured (Blau, 1955; Lawler, 1976). In this case, with no formal performance measures in place, Final Assembly team members had no reason to emphasize one source of information over others, including their own direct perception of how well the group was performing. For example, informal complaints from other groups may have been ignored by the team if measures focused narrowly on the volume of frames assembled.

Third, team members described informal performance criteria in relatively abstract terms, similar to how they described "good" and "not so good" behaviors in the earlier group norm results. Just as helping is an abstract norm that is generically applicable to 
diverse team situations, the subjective performance criteria identified in Table 5keeping caught up, avoiding complaints from others, maintaining a smooth, problemfree operation, etc.-are also abstract and generic in applicability. The similarity in level of abstraction at which team members conceived of performance criteria and group norms suggests a potential relationship between the two. Achieving such diverse and generic performance objectives may depend on the willingness of individuals to do whatever is necessary under the circumstances to avoid falling behind, generating complaints, or creating problems - in effect a willingness to help where needed. The absence of specific performance measures may have encouraged members to take a general rather than narrow view of their jobs, strengthening their expectations on one another to help wherever needed.

\section{Department Size, Product Size, Turnover, and Management Style}

Other aspects of the team's task situation, which were observed during the study but not directly examined in the interviews, may have also influenced team behavior and effectiveness. These include the small size of the team, the small physical space occupied by the department, the large size of the products, the low rate of employee turnover, and the department manager's style and decisions.

As a group of only ten individuals, team members interacted frequently and knew each other well. Because group norms develop through repeated member interaction, the small size would have contributed to norm strength, in terms of both the high degree of consistency to which a norm like helping was shared among members and the motivational effects of norms on member behavior.

The Final Assembly department also occupied a relatively small physical space, such that all members could usually see each other and come to one another's aid within a few seconds if necessary. Meanwhile, its products were quite large, making it easy to see what other team members were doing. Frames were shaped like tall rectangular boxes approximately $1 \mathrm{~m}$ by $0.5 \mathrm{~m}$ by $2.5 \mathrm{~m}$ high; circuit packs were roughly $0.5 \mathrm{~m}$ square by $2-3 \mathrm{~cm}$ thick. These physical characteristics may have supported the development of a strong group helping norm because the small workspace and large products made it easy to see when other members required assistance, and close proximity made it easy to provide help when the need arose.

Team membership turnover was low in Final Assembly compared to other factory departments. In fact, we observed no turnover during the six month period of study. Team turnover includes both employment turnover (due to hiring, firing, resigning, etc.) and within-factory turnover when individuals switch jobs from one team to another. Some prior research has interpreted low employment turnover as a positive outcome of team effectiveness (Cohen \& Bailey, 1997). However, the department manager indicated that turnover had been traditionally low in Final Assembly, well before the unit began operating as a self-directed team. The suggested reason was that Final Assembly jobs were relatively desirable within the factory, because the large products let employees walk around and work standing up. By contrast, jobs in the Circuit Pack 
department involved sitting at crowded assembly lines, inserting tiny components onto printed circuit boards, and often resulted in stiffness and back strain. Union rules specified that jobs were assigned based on worker seniority and since team members had relatively high seniority, they were unlikely to get "bumped" from their jobs by other workers seeking a job transfer. Rather than a behavioral outcome of team effectiveness, therefore, it is more reasonable to consider low team turnover (i.e., membership stability) as a potential antecedent to team effectiveness in this case (Hackman, Wageman, Ruddy, \& Ray, 2000). Because the length of time a group of people work together should influence the strength and stability of norms, low turnover likely supported norm development.

Finally, the department manager influenced team behavior through her decisions and management style. Her decision not to replace the fired first level manager clearly differentiated her own responsibilities from those of the team. Team members were responsible for daily department operations, including task assignments, work scheduling, conflict resolution among members, payroll administration and other paperwork, and most interactions with other departments. The department manager, who also managed a number of production support departments like Packaging and Shipping, dealt with relations between the team and upper management, and helped the team solve problems beyond its control. Although this particular division of responsibilities may seem obvious, the question of which responsibilities to assign to teams was a concern for some first level managers elsewhere in the factory, who worried that they might be working themselves out of jobs by encouraging self-directed teams.

Other aspects of the department manager's style are also notable. In team meetings she repeatedly articulated to members the nature of their responsibilities as distinct from her own. For example, when a conflict arose between two members, she flatly refused to get involved, stating that they had to work it out for themselves within the team. At the same time, she gave the team a great deal of encouragement and positive feedback on their performance. She also granted team members relatively more latitude in how they structured their time than workers were given in other departments, for instance accommodating one member's need for flexible work hours to meet family commitments by allowing her to start and end her shift an hour earlier than others. Although potentially disruptive to factory schedules, such accommodations were appreciated by team members and explicitly mentioned during interviews as examples of helpful managerial behaviors. Like reciprocal helping between team members, such managerial behavior may have encouraged reciprocation on the part of team members through their efforts to keep the operation running smoothly.

The department manager also helped the team perform its routine activities by acting as a buffer between it and other factory departments (Lipman-Blumen \& Leavitt, 1999). Although she expected the team to deal directly with other departments rather than to involve her, she often worked behind the scenes to ensure smooth relations and to diffuse potential conflicts. For example, when other departments encountered team implementation difficulties, the perceived success of the Final Assembly team led to 
jealousy and uncooperative behavior on the part of some first-level managers. By using her higher rank to pressure these managers in private, she was able to coerce them to cooperate with team members and thereby shield the team from certain effects of interdepartmental politics. When conflicts were unavoidable she made it clear that she supported the team, even at personal risk to her own career. On one occasion, we observed a senior manager from another department interrupt a Final Assembly team meeting and demand that they vacate the room which he needed for what he called a "more important" meeting. Despite his more senior rank, the department manager refused to vacate the room and publicly berated this manager in front of team members for being disrespectful of their work, which she described as "just as important".

\section{Discussion}

\section{Summary of Results}

The objectives of this study were to characterize the Final Assembly team's effectiveness in behavioral terms and to identify aspects of the team's task situation that may have influenced its behavioral characteristics. The results provide substantial evidence to support the perceptions of factory management and support staff that the Final Assembly team performed effectively. Positive team behaviors exceeded negative behaviors by a large margin, and the findings indicated high group autonomy, high positive affect among members, strong member identification with the team, and high cohesiveness-all commonly associated with team effectiveness in the literature. Factory performance data were unreliable as discussed, but members' subjective perceptions of team performance suggested they defined effectiveness in terms of meeting the expectations of the diverse factory groups with whom they interacted.

The study provided substantial evidence of the team's behavioral characteristics. Helping among team members was a particularly significant behavioral norm identified repeatedly in the results. Four important properties of this norm are worth mentioning. First, we have already noted that helping was a kind of generic meta-norm applicable to diverse behavioral circumstances likely to be encountered by the team. Second, helping was a strong norm in terms of its manifestation in behavior: each member was very likely to provide help to other members when necessary. Third, helping was primarily a task-related norm in that it defined behavioral expectations associated with the performance of job activities (as opposed to non-task interactions such as lunch break routines, etc.). Fourth, helping was a positive or pro-organizational norm in the sense that normative behavior was generally consistent with performance expectations placed on the team by management and other organizational groups. Although many groups exhibit autonomy, cohesiveness, strong member identification and positive affect among members, not all such groups also exhibit strong task-related norms encouraging behavior consistent with organizational performance expectations. Thus, the behavioral attribute that most distinctly characterized the Final Assembly team's effectiveness was its strong, positive, task-related meta-norm of helping each other where needed. The question of how the team's task situation may have influenced its behavior can, 
therefore, be stated more precisely as a question of how aspects of the situation supported helping behavior among team members. The study results summarized in Table 6 suggest many properties of the Final Assembly task situation combined to create a context supportive of helping as a strong team norm.

\section{Table 6: Summary of results}

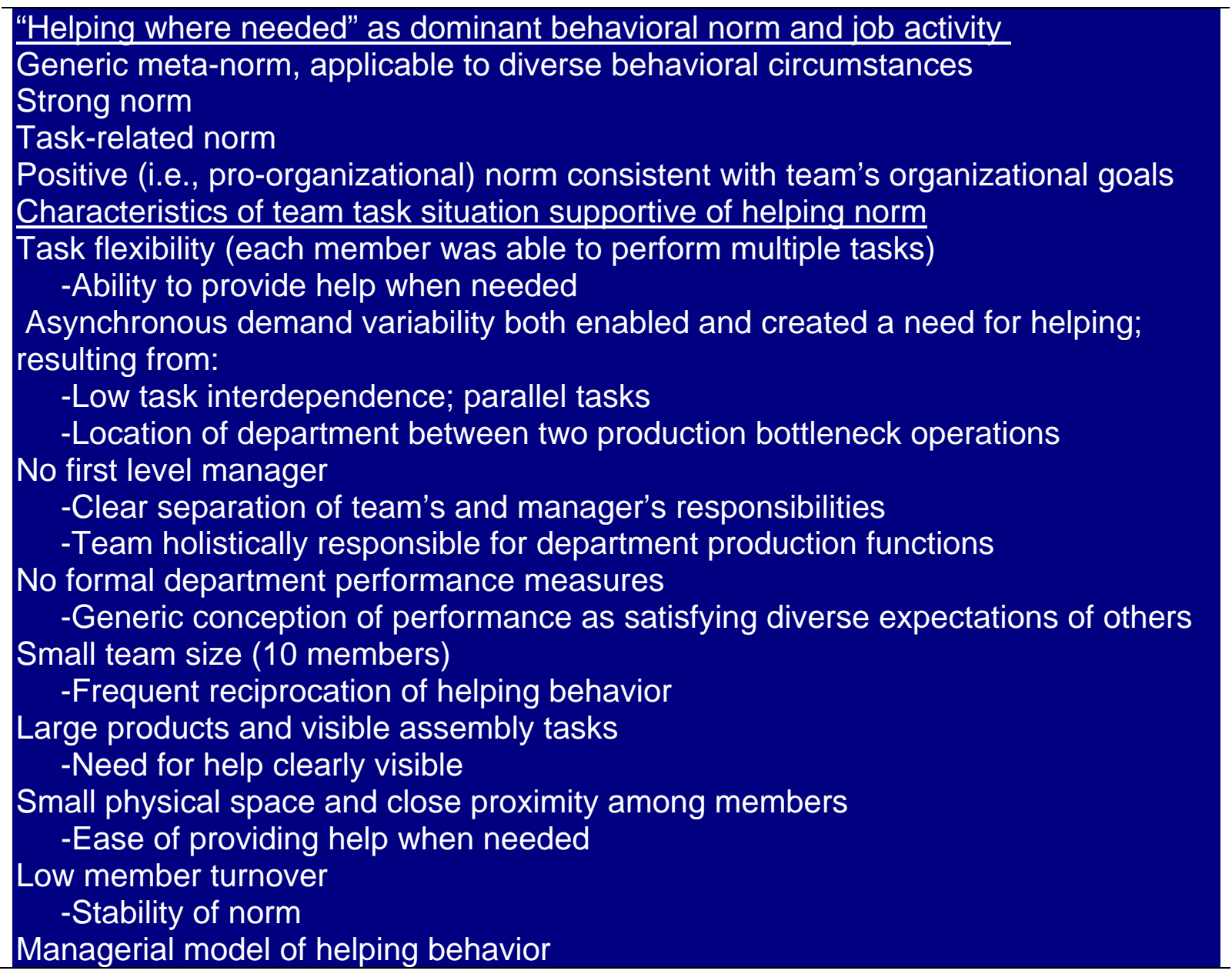

\section{$\underline{\text { Research and Managerial Implications }}$}

The case study raises theoretical questions about the role of helping behavior in teams and the relationship between the properties of a team's task situation and team behavior. As a qualitative case study of a single team in one organization, our findings provide no basis for causal claims, but the results in Table 6 suggest a number of questions for future research. Does helping as a group norm generalize to effective teams in other settings? Under what circumstances would helping be inappropriate within teams? Do the situational characteristics identified in the present study have systematic effects on the prevalence of helping behavior that generalize to other 
settings? Are different team task situations associated with different kinds of helping behavior?

Researchers have paid increasing attention to helping behavior in organizations, but have not generally viewed helping as a central characteristic of effective teams. Instead, the organizational citizenship literature has viewed helping as a discretionary extra-role behavior (Organ, Podsakoff, \& MacKenzie, 2006; Smith, Organ, \& Near, 1983) and the contextual performance literature views it as a type of behavior separate from employee tasks (Borman \& Motowidlo, 1993; Motowidlo \& Van Scotter, 1994; Organ, 1997). But the fact that helping was identified most frequently by Final Assembly team members as a positive behavior and as a basic job activity makes it clear that helping was both a normative in-role behavior and central to how team members conceived of their tasks. The OCB literature is also inexplicit about the recipients of helping behavior, but our findings indicate that team members did not direct their helping toward all others in the organization with whom they interacted on the job. Instead, their helping was directed selectively toward other team members, while interactions with external groups were generally more negative in nature.

We would argue differences between our findings and other research have to do with our focus on the relationship between team behavior and properties of the team task situation. The team effectiveness and OCB literatures have paid relatively little attention to situational influences on helping behavior in teams, yet our results indicate these influences may be quite significant and, in some case, theoretically counterintuitive. For example, literature has traditionally held that task interdependence, not independence, is likely to contribute to team effectiveness (Cohen \& Bailey, 1997; Procter \& Currie, 2004), but our results suggest that objective task independence created conditions conducive to helping, which in turn may have contributed to subjective perceptions of high task interdependence (as indicated by the hockey versus swim team ratings for instance). This suggests an important distinction between objective and subjective perceptions of task interdependence, which has not been acknowledged in prior research, and that perceptions of task interdependence may be a consequence of team behavior in certain cases rather than an antecedent. Outcome interdependence, referring to collectively defined group goals (Campion, Medsker, \& Higgs, 1993; Wageman, 1995), may partly account for the relationship between objective and subjective task interdependence in this study. As part of a formally designated team with collectively defined performance expectations, team members were interdependent with respect to group outcomes, which presumably encouraged them to be particularly helpful to one another, rather than to individuals outside the team with whom their tasks were more directly connected. That is, outcome interdependence defined who to help and helping led to subjective perceptions of task interdependence in a situation of objective task independence.

Such findings point to the need for further research on how properties of group task structures, such as task interdependence, work flow arrangements, capacity bottlenecks and demand variability, influence team member behavior, norms and effectiveness. In the present study, helping amounted to the sharing of work among team members a 
behavior consistent with asynchronous demands resulting from parallel task arrangements and the team's location in the factory work flow between two bottlenecks. But different task structures might be associated with different forms of helping. For example, in sequentially related tasks demand variability would be closely synchronized between team members, limiting their flexibility to help each other by sharing work loads. Instead, co-workers might be expected to help one another at the points of interface between sequential tasks, for instance by ensuring that the work output of one task is provided in ways that best fit the input constraints of the next.

The significance of helping as a group norm in the Final Assembly team suggests research should also be directed toward a better understanding of the relationships between helping behavior and traditional social psychological properties of groups identified in the literature, such as autonomy, skill variety, member identification, and cohesiveness. For example, it seems reasonable to hypothesize reciprocal effects whereby such psychosocial factors influence the prevalence of helping, and helping also influences group ratings on these variables. If so, helping may play a particularly important role in newly formed groups, where the initial development of these group properties may depend on the extent to which members help one another through difficult circumstances and come to depend on one another for help.

Finally, the study has implications for managers wishing to encourage helping behavior in teams. The results identified many characteristics of the Final Assembly team's task situation that seem to have supported the emergence of helping as a strong behavioral norm, suggesting that managers may be able to encourage effective team behavior by deliberately designing task situations conducive to helping. It would be inappropriate simply to replicate the specific situational characteristics identified here in different settings without further research, but it may be possible to identify general properties of task situations that support team helping behavior, based on the current results. For example, it seems essential that team members possess the requisite skills or knowledge to be able to provide appropriate help when the need arises, a view consistent with prior studies suggesting skill diversity relates positively to team performance (Campion, Medsker, \& Higgs, 1993; Magjuka \& Baldwin, 1991). Second, team members must have sufficient job flexibility to be able to drop what they are doing temporarily when other members require help, without worrying about falling behind in their own work or being sanctioned by management. Such flexibility could derive from task independence, a position between workflow bottlenecks, or various other potential sources. A third requirement is an efficient means of communicating the need for help among team members. Direct observation of work involving large products at close proximity was the primary means of communication in this study, but other methods can be easily imagined. A fourth requirement is a sufficient degree of role clarity among members with respect to their group responsibilities and performance expectations, so that members understand what behaviors are likely to be helpful and unhelpful. The lack of a first level manager appears to have signaled to Final Assembly team members that helping was a significant role expectation and also served to define what sorts of behaviors were helpful and unhelpful. The lack of formal performance measures also seems to have encouraged members to view their performance holistically in terms of 
satisfying the diverse expectations of others in the team's immediate environment. Such unique properties of the Final Assembly situation are likely infeasible for most organizations, and suggest that more research is needed to examine the influence of supervisory roles and performance measures on role clarity and helping behavior in teams. Presumably sufficient role clarity can be established without eliminating first level managers, yet certain managerial styles and structures are likely more effective than others.

\section{Conclusion}

This study has provided a detailed view of the behavioral characteristics and norms of an effective self-directed work team. Inductive case methods were used to examine team member behavior and interactions in relation to properties of the team's task situation. While some of the results are consistent with past research, others suggest much remains to be learned about how team members behave and about the situational influences on team behavior. The findings indicate that helping was the dominant behavioral norm in the Final Assembly team and that the team's task situation exhibited numerous characteristics consistent with the development and encouragement of this norm. As a group norm, helping had several properties consistent with managerial conceptions of team effectiveness and performance. It was a generic meta-norm applicable to diverse work situations likely to be encountered by the team. It was also a strong task-related norm that encouraged behavior consistent with organizational goals. Future research is needed to examine the extent to which either the helping norm or the situational factors identified in the present study generalize to other team settings. As more is learned about the relationship between task situation and team behavior, managers may be able to design work situations that support and encourage the sorts of norms most consistent with the goals operating in specific organizational settings.

\section{References}

Abelson, R. P. (1976). Script processing in attitude formation and decision making. In J. S. Carroll \& J. Payne (Eds.), Cognition and Social Behavior (pp. 139-181). Hillsdale, NJ: Lawrence Erlbaum.

Ancona, D. G. (1990). Outward bound: strategies for team survival in an organization. Academy of Management Journal, 33(2), 334-365.

Argyris, C. (1969). The incompleteness of social psychological theory: Examples from small group, cognitive consistency, and attribution research. American Psychologist, 24, 893-908.

Bavelas, A. (1942). A method for investigating individual and group ideology. Sociometry, 5, 371-377. 
Bettenhausen, K. L., \& Murnighan, J. K. (1985). The emergence of norms in competitive decision-making groups. Administrative Science Quarterly, 30, 350-372.

Bishop, J. W., Scott, K. D., \& Burroughs, S. M. (2000). Support, commitment, and employee outcomes in a team environment. Journal of Management, 26, 1113-1132.

Blau, P. M. (1955). The dynamics of bureaucracy. Chicago: University of Chicago Press.

Borman, W. C., \& Motowidlo, S. J. (1993). Expanding the criterion domain to include elements of contextual performance. In N. Schmitt \& W. C. Borman (Eds.), Personnel selection in organizations (pp. 71-98). San Francisco: Jossey-Bass.

Bunderson, J. S., \& Sutcliffe, K. M. (2002). Comparing alternative conceptualizations of functional diversity in management teams: process and performance effects. Academy of Management Journal, 45, 875-893.

Campion, M. A., Medsker, G. J., \& Higgs, A. C. (1993). Relations between work group characteristics and effectiveness: implications for designing effective work groups. Personnel Psychology, 46, 823-850.

Cohen, S. G., \& Bailey, D. E. (1997). What makes teams work: group effectiveness research from the shop floor to the executive suite. Journal of Management, 23(3), 239290.

Cohen, S. G., \& Ledford, G. E. (1994). The effectiveness of self-managing teams: a quasi-experiment. Human Relations, 47, 13-43.

Cohen, S. G., Ledford, G. E., \& Spreitzer, G. M. (1996). A predictive model of selfmanaging work team effectiveness. Human Relations, 49(5), 643-676.

Cunningham, J. B. (2001). Researching organizational values and beliefs. The Echo approach. Westport, CT: Quorum.

Deckop, J. R., Cirka, C. C., \& Andersson, L. M. (2003). Doing unto others: The reciprocity of helping behavior in organizations. Journal of Business Ethics, 47, 101113.

Evans, C. R., \& Dion, K. L. (1991). Group cohesion and performance: a meta-analysis. Small Group Research, 22(2), 175-186.

Fahr, J. L., Podsakoff, P. M., \& Organ, D. W. (1990). Accounting for organizational citizenship behavior: Leader fairness and task scope versus satisfaction. Journal of Management, 16(4), 705-721. 
Feldman, D. C. (1984). The development and enforcement of group norms. Academy of Management Review, 9, 47-53.

Gersick, C. J. G. (1988). Time and transition in work teams: Toward a new model of group development. Academy of Management Journal, 31(1), 9-41.

Gersick, C. J. G., \& Hackman, J. R. (1990). Habitual routines in task-performing groups. Organizational Behavior and Human Decision Processes, 47(1), 65-97.

Gully, S. M., Devine, D. S., \& Whitney, D. J. (1995). A meta-analysis of cohesion and performance: effects of level of analysis and task interdependence. Small Group Research, 26(4), 497-520.

Guzzo, R. A., \& Dickson, M. W. (1996). Teams in organizations: recent research on performance and effectiveness. Annual Review of Psychology, 47, 307-338.

Hackman, J. R. (1987). The design of work teams. In J. W. Lorsch (Ed.), Handbook of Organizational Behavior (pp. 315-342). Englewood Cliffs, NJ: Prentice Hall.

Hackman, J. R., \& Morris, C. G. (1975). Group tasks, group interaction process, and group performance effectiveness: a review and proposed integration. In L. Berkowitz (Ed.), Advances in Experimental Social Psychology (Vol. 9, pp. 45-99). New York: Academic Press.

Hackman, J. R., Wageman, R., Ruddy, T. M., \& Ray, C. L. (2000). Team effectiveness in theory and in practice. In C. Cooper \& E. A. Locke (Eds.), Industrial and organizational psychology : theory with practice (pp. 109-129). Oxford: Blackwell.

Ilgen, D. R., Hollenbeck, J. R., Johnson, M., \& Jundt, D. (2005). Teams in organizations: from input-process-output models to IMOI models. Annual Review of Psychology, 56, 517-543.

Jehn, K. (1995). A multimethod examination of the benefits and detriments of intragroup conflict. Administrative Science Quarterly, 40(2), 245-282.

Johnson, D. W. (1973). Communication in conflict situations: a critical review of the research. International Journal of Group Tensions, 3, 46-67.

Kelly, J. R., \& McGrath, J. E. (1985). Effects of time limits and task types on task performance and interaction in four-person groups. Journal of Personality and Social Psychology, 49, 395-407.

Kiggundu, M. N. (1983). Task interdependence and job design: test of a theory. Organizational Behavior and Human Performance, 31, 145-172. 
King, E. B., George, J. M., \& Hebl, M. R. (2005). Linking personality to helping behaviors at work: An interactional perspective. Journal of Personality, 73(3), 585-607.

Lawler, E. E. (1976). Control Systems in Organizations. In M. D. Dunnette (Ed.), Handbook of Industrial and Organizational Psychology (pp. 1247-1291). Chicago: Rand McNally.

Levine, J. M., \& Moreland, R. L. (1990). Progress in small group research. Annual Review of Psychology, 41, 585-634.

Lipman-Blumen, J., \& Leavitt, H. J. (1999). Hot groups: seeding them, feeding them, \& using them to ignite your organization. New York: Oxford University Press.

Magjuka, R. J., \& Baldwin, T. T. (1991). Team-based employee involvement programs: effects of design and administration. Personnel Psychology, 44, 793-812.

McClelland, C. L. (1984). The development and persistence of routinized group decision making. Unpublished doctoral dissertation, Purdue University, West Lafayette, IN.

Motowidlo, S. J., \& Van Scotter, J. R. (1994). Evidence that task performance should be distinguished from contextual performance. Journal of Applied Psychology, 79(4), 475480 .

Mullen, B., Anthony, T., Salas, E., \& Driskell, J. E. (1993). Group cohesiveness and quality in decision making: an integration of tests of the groupthink hypothesis. Small Group Research, 25(2), 189-204.

Mullen, B., \& Copper, C. (1994). The relation between group cohesiveness and performance: an integration. Psychological Bulletin, 115(2), 210-227.

Nieva, V. F., Fleishman, E. A., \& Reick, A. (1985). Team dimensions: their identity, their measurement, and their relationship. Washington, DC: US Army Research Institute for Behavioral and Social Sciences.

Organ, D. W. (1997). Organizational citizenship behavior: It's construct clean-up time. Human Performance, 10(2), 85-97.

Organ, D. W., Podsakoff, P. M., \& MacKenzie, S. B. (2006). Organizational citizenship behavior: Its nature, antecedents, and consequences. Thousand Oaks, CA: Sage.

Organ, D. W., \& Ryan, K. (1995). A meta-analytic review of attitudinal and dispositional predictors of organizational citizenship behavior. Personnel Psychology, 48(4), 775-802.

Pearce, J. L., \& Gregersen, H. B. (1991). Task interdependence and extrarole behavior: A test of the mediating effects of felt responsibility. Journal of Applied Psychology, 76(6), 838-844. 
Podsakoff, P. M., Ahearne, M., \& MacKenzie, S. B. (1997). Organizational citizenship behavior and the quantity and quality of work group performance. Journal of Applied Psychology, 82(2), 262-270.

Podsakoff, P. M., MacKenzie, S. B., \& Bommer, W. H. (1996). A meta-analysis of the relationships between Kerr and Jermier's substitutes for leadership and employee attitudes, role perceptions, and performance. Journal of Applied Psychology, 81, 380399.

Podsakoff, P. M., Mackenzie, S. B., Paine, J. B., \& Bachrach, D. G. (2000). Organizational citizenship behaviors: A critical review of the theoretical and empirical literature and suggestions for future research. Journal of Management, 26(3), 513-563.

Porter, C. O. L. H., Hollenbeck, J. R., Ilgen, D. R., Ellis, A. P. J., \& West, B. J. (2003). Backing up behavior in teams: the role of personality and legitimacy of need. Journal of Applied Psychology, 88, 391-403.

Procter, S., \& Currie, G. (2004). Target-based teamworking: groups, work and interdependence in the UK civil service. Human Relations, 57(12), 1547-1572.

Roethlisberger, F. J., \& Dickson, W. J. (1956). Management and the Worker: an account of a research program conducted by the Western Electric Company, Hawthorne Works, Chicago. Cambridge, MA: Harvard University Press.

Sanna, L. J., \& Parks, C. D. (1997). Group research trends in social and organizational psychology: Whatever happened to intragroup research? Psychological Science, 8, 261-267.

Seers, A., Petty, M. M., \& Cashman, J. F. (1995). Team-member exchange under team and traditional management: a naturally occurring quasi-experiment. Group and Organization Management, 20(1), 18-38.

Smith, C. A., Organ, D. W., \& Near, J. P. (1983). Organizational citizenship behavior: Its nature and antecedents. Journal of Applied Psychology, 68, 653-663.

Sparrowe, R. T., Soetjipto, B. W., \& Kraimer, M. L. (2006). Do leaders' influence tactics relate to member helping behavior? It depends on the quality of the relationship. Academy of Management Journal, 49(6), 1194-1208.

Steiner, I. D. (1972). Group process and productivity. New York: Academic Press.

Thompson, J. D. (1967). Organizations in action. New York: McGraw-Hill.

Trist, E. L., \& Bamforth, K. W. (1951). Some social and psychological consequences of the longwall method of coal-getting. Human Relations, 4(1), 4-38. 
Vinokur-Kaplan, D. (1995). Treatment teams that work (and those that don't): an application of Hackman's group effectiveness model to interdisciplinary teams in psychiatric hospitals. Journal of Applied Behavioral Science, 31(3), 303-327.

Wageman, R. (1995). Interdependence and group effectiveness. Administrative Science Quarterly, 40(1), 145-180.

Wageman, R. (2001). How leaders foster self-managing team effectiveness: design choices vs. hands-on coaching. Organization Science, 12, 559-577.

Walz, S. M., \& Niehoff, B. P. (2000). Organizational citizenship behaviors: Their relationship to organizational effectiveness. Journal of Hospitality and Tourism Research, 24, 301-319.

Whyte, W. F. (1955). Money and Motivation. New York: Harper.

Williams, L. J., \& Anderson, S. E. (1991). Job satisfaction and organizational commitment as predictors of organizational citizenship behavior. Journal of Management, 17, 601-617. 